\title{
Associations of TAP1 genetic polymorphisms with atopic diseases: asthma, rhinitis and dermatitis
}

\author{
Rongzeng Liu ${ }^{1, *}$, Xiafei Chen ${ }^{2, *}$ and Jingjiao $Q \mathbf{~}^{1}$ \\ ${ }^{1}$ Department of Immunology, Medical College, Henan University of Science and Technology, Luoyang, China \\ ${ }^{2}$ Network Information Center, Henan University of Science and Technology, Luoyang, China \\ * These authors have contributed equally to this work \\ Correspondence to: Rongzeng Liv, email: rongzengliu@outlook.com \\ Keywords: TAP1; polymorphism; atopic diseases; atopic dermatitis; allergic rhinitis; Immunology \\ Received: July 18, $2017 \quad$ Accepted: December 06, $2017 \quad$ Published: December 20, 2017 \\ Copyright: Liu et al. This is an open-access article distributed under the terms of the Creative Commons Attribution License 3.0 (CC BY \\ 3.0), which permits unrestricted use, distribution, and reproduction in any medium, provided the original author and source are credited.
}

\section{ABSTRACT}

Controversial findings have been reported regarding to the effect of the transporter associated with antigen processing 1 (TAP1) polymorphisms exerted on the atopic diseases susceptibility. To gain a better understanding of the effects of TAP1 polymorphisms on the risk of atopic diseases, a retrospective study was carried out to evaluate the association of the most common TAP1 polymorphisms, rs1057141 and rs1135216, with the risk of atopic diseases. From studies published in PubMed, Embase, and Web of Science up to July 2017, ten eligible studies were selected for meta-analysis. The pooled results from rs1135216 polymorphism showed increased risk of atopic diseases in homozygote and recessive comparison. From the subgroup analysis by ethnicity, it was found that rs1135216 polymorphism contributed to atopic diseases susceptibility among Africans in all the five genetic models. Subgroup analysis by atopic types indicated significant association of TAP1 polymorphism rs1135216 with asthma in the allele, dominant and recessive models and with allergic rhinitis in the recessive model. As to rs1057141, increased risk of atopic disease in the allelic, dominant and heterozygous model was found in African population. Overall, this meta-analysis study demonstrated that rs1135216 polymorphism may contribute to atopic diseases susceptibility in Asians and Africans as assessed in this study. However, well designed large-scale case-control studies are needed to confirm such preliminary findings.

\section{INTRODUCTION}

Atopic diseases which include atopic dermatitis(AD), allergic rhinitis(AR), and asthma(AA) are closely related. Allergic rhinitis is often present in asthmatics and the incidence of asthma development in individuals suffering from allergic rhinitis is five times of those bearing no allergic rhinitis [1]. It has been reported that allergic symptoms could start with atopic dermatitis in infancy followed by allergic rhinitis and asthma later in life [2]. In addition, development of atopic diseases is attributed to genetic and environmental factors in a great extent [3].

It has been proposed that TAP gene may be responsible for atopic disease susceptibility.
Polymorphisms in TAP1 may affect antigen recognition and presentation, potentially resulting in low expression or entirely absence of MHC-I at the cell surface, which could ultimately lead to an adverse immune response [4]. Studies on the polymorphisms of the TAP1 gene in several human leukocyte antigen (HLA)-associated diseases such as atopic dermatitis, asthma, rhinitis [5-14] found that rs 1057141 and rs1135216 as the most common single nucleotide polymorphisms. Currently, controversial opinions are presented for the relationships between TAP1 gene polymorphisms and atopic diseases. This may be resulted from the moderate sample size of the previous studies which could not provide inclusive findings. Therefore, to gain a more comprehensive insight of the association of TAP1 polymorphisms with the development 
of atopic diseases, our study performed a set of metaanalysis by utilizing pooled data from selected studies on the association of two TAP1 polymorphisms rs1057141 and rs1135216 and atopic diseases.

\section{RESULTS}

\section{Study characteristics}

By following literature selection process as illustrated in Figure 1, 138 studies were identified from PubMed, Embase and Web of Science databases (PubMed: 20, Embase: 30, Web of Science: 88). Subsequently, 126 articles were excluded due to duplication $(n=24)$ or without relation to this topic $(n=102)$. Following detailed evaluation of the remaining twelve studies, four studies were excluded with one being lack of relation to rs1057141 or rs1135216 polymorphism [15], one not being a case-control study [16], and two lack of enough pertinent data $[8,14]$. A total of 8 articles, with 7 published in English and 1 in Chinese, were included for qualitative synthesis based on the inclusion and exclusion criteria [5-7, 9-13]. One of the articles was further separated into three studies because it examined different atopic types [7] (Table 1). Therefore, in total, data from 10 case-control studies, amounting to 661 cases and 876 controls for rs 1057141 and 668 cases and 876 controls for rs 1135216 , were pooled into the meta-analysis. Of these, there were 4 studies of atopic dermatitis, 4 studies of allergic rhinitis, and 2 studies of asthma. Characteristics of studies

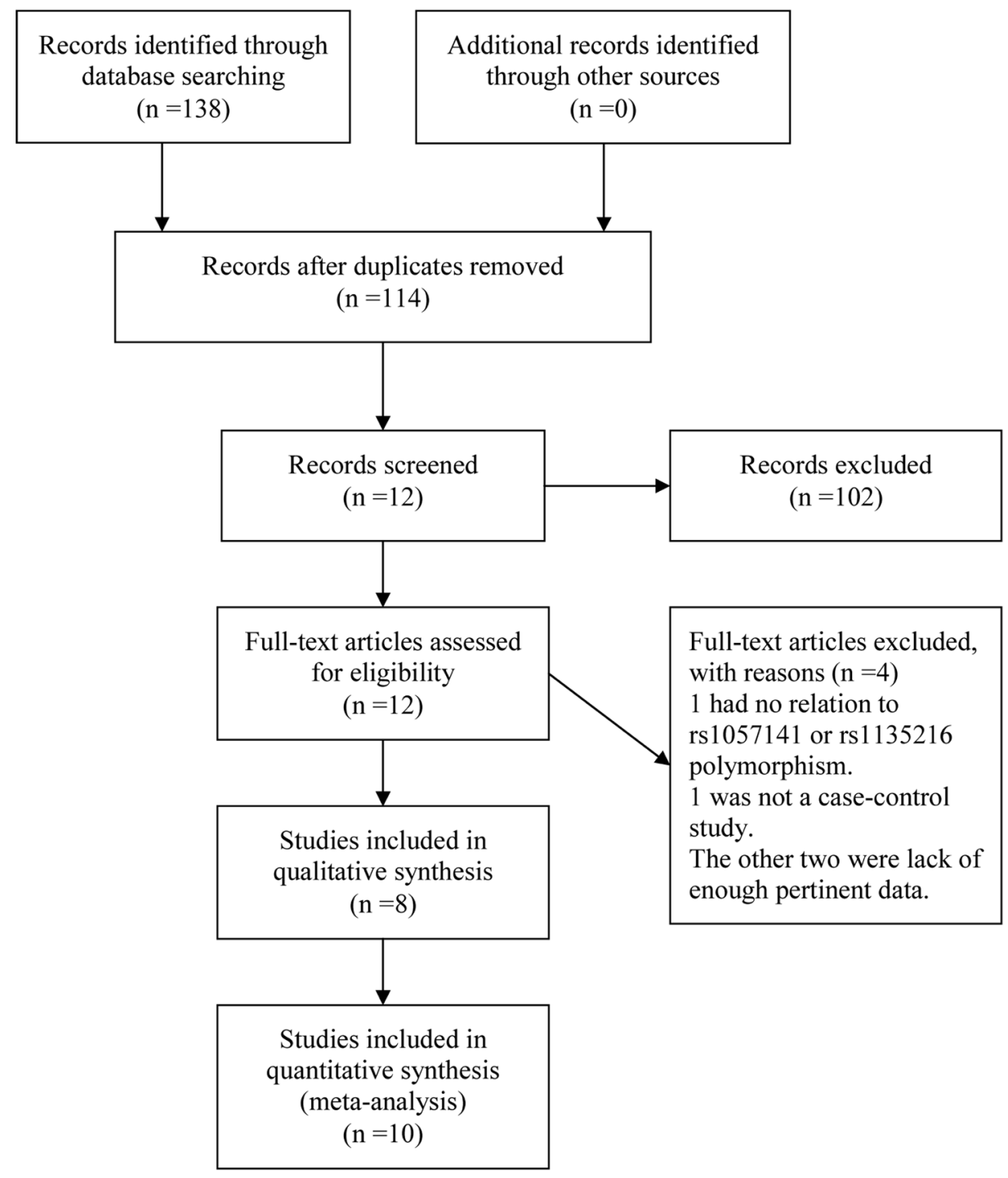

Figure 1: Workflow for literature selection. 
Table 1: Characteristics of studies in the meta-analysis

\begin{tabular}{|c|c|c|c|c|c|c|c|c|c|c|c|c|c|c|}
\hline \multirow{2}{*}{ Author } & \multirow{2}{*}{ year } & \multirow{2}{*}{ Location } & \multirow{2}{*}{ Ethnicity } & \multirow{2}{*}{ Atopic type } & \multirow{2}{*}{ Genotyping } & \multicolumn{4}{|c|}{ TAP1 rs1057141 Case/Control } & \multicolumn{4}{|c|}{ TAP1 rs1135216 Case/Control } & \multirow{2}{*}{ NOS } \\
\hline & & & & & & $\mathbf{A A}$ & AG & GG & HWE & $\mathbf{A A}$ & AG & GG & HWE & \\
\hline Chen & 2012 & China & Asia & $\mathrm{AR}$ & SNaPshot & $96 / 99$ & $50 / 45$ & $4 / 6$ & 0.756 & $104 / 107$ & $43 / 41$ & $3 / 2$ & 0.379 & 11 \\
\hline Kim & 2007 & Korea & Asia & $\mathrm{AR}$ & ARMS & $82 / 54$ & $26 / 53$ & $2 / 0$ & 0.001 & $76 / 55$ & $30 / 50$ & $4 / 2$ & 0.014 & 8 \\
\hline Hang & 2003 & Taiwan & Asia & $\mathrm{AA}$ & RFLP & $58 / 25$ & $45 / 15$ & $6 / 3$ & 0.719 & $76 / 37$ & $39 / 6$ & $1 / 0$ & 0.623 & 10 \\
\hline Takeuchi & 2002 & Japan & Asia & $\mathrm{AR}$ & ARMS & $50 / 50$ & 9/11 & $1 / 1$ & 0.666 & $46 / 42$ & $12 / 19$ & $2 / 1$ & 0.482 & 11 \\
\hline Lee & 2001 & Korea & Asia & $\mathrm{AD}$ & SSCP & $34 / 113$ & $16 / 60$ & $3 / 11$ & 0.427 & $36 / 125$ & $15 / 55$ & $2 / 4$ & 0.469 & 9 \\
\hline Ismail & 1997 & Tunisia & Africa & AA & ARMS & $31 / 65$ & $15 / 14$ & $2 / 2$ & 0.261 & $19 / 62$ & $6 / 16$ & $23 / 3$ & 0.159 & 10 \\
\hline Ismail & 1997 & Tunisia & Africa & $\mathrm{AR}$ & ARMS & $24 / 65$ & $21 / 14$ & $0 / 2$ & 0.261 & $19 / 62$ & $15 / 16$ & $11 / 3$ & 0.159 & 10 \\
\hline Ismail & 1997 & Tunisia & Africa & $\mathrm{AD}$ & ARMS & $12 / 65$ & $6 / 14$ & $2 / 2$ & 0.261 & $8 / 62$ & $9 / 16$ & $3 / 3$ & 0.159 & 10 \\
\hline Kuwata & 1995 & Japan & Asia & $\mathrm{AD}$ & RFLP & $27 / 38$ & $9 / 12$ & $1 / 2$ & 0.413 & $28 / 39$ & $8 / 11$ & $1 / 2$ & 0.302 & 8 \\
\hline Kuwata & 1994 & Japan & Asia & $\mathrm{AD}$ & RFLP & $21 / 28$ & $8 / 7$ & $0 / 0$ & 0.511 & $26 / 22$ & $3 / 13$ & $0 / 0$ & 0.177 & 8 \\
\hline
\end{tabular}

$\mathrm{AD}$, atopic dermatitis; AR, allergic rhinitis; AA, asthma; ARMS, amplification refractory mutation system; RFLP, restriction fragment length polymorphism; SSCP, single-strand conformation polymorphism; HWE, Hardy-Weinberg Equilibrium; NOS, Newcastle-Ottawa Scale.

investigating the relationship between rs1057141 and rs1135216 single nucleotide polymorphism and atopic diseases are summarized in Table 1. For all the studies, genomic DNA isolated from blood samples was used for genotyping, for which PCR-ARMS assay were used in five studies; PCR-RFLP method were applied in three studies, PCR-SSCP assay was used in one study, and SNaPshot system assay was used in one study.

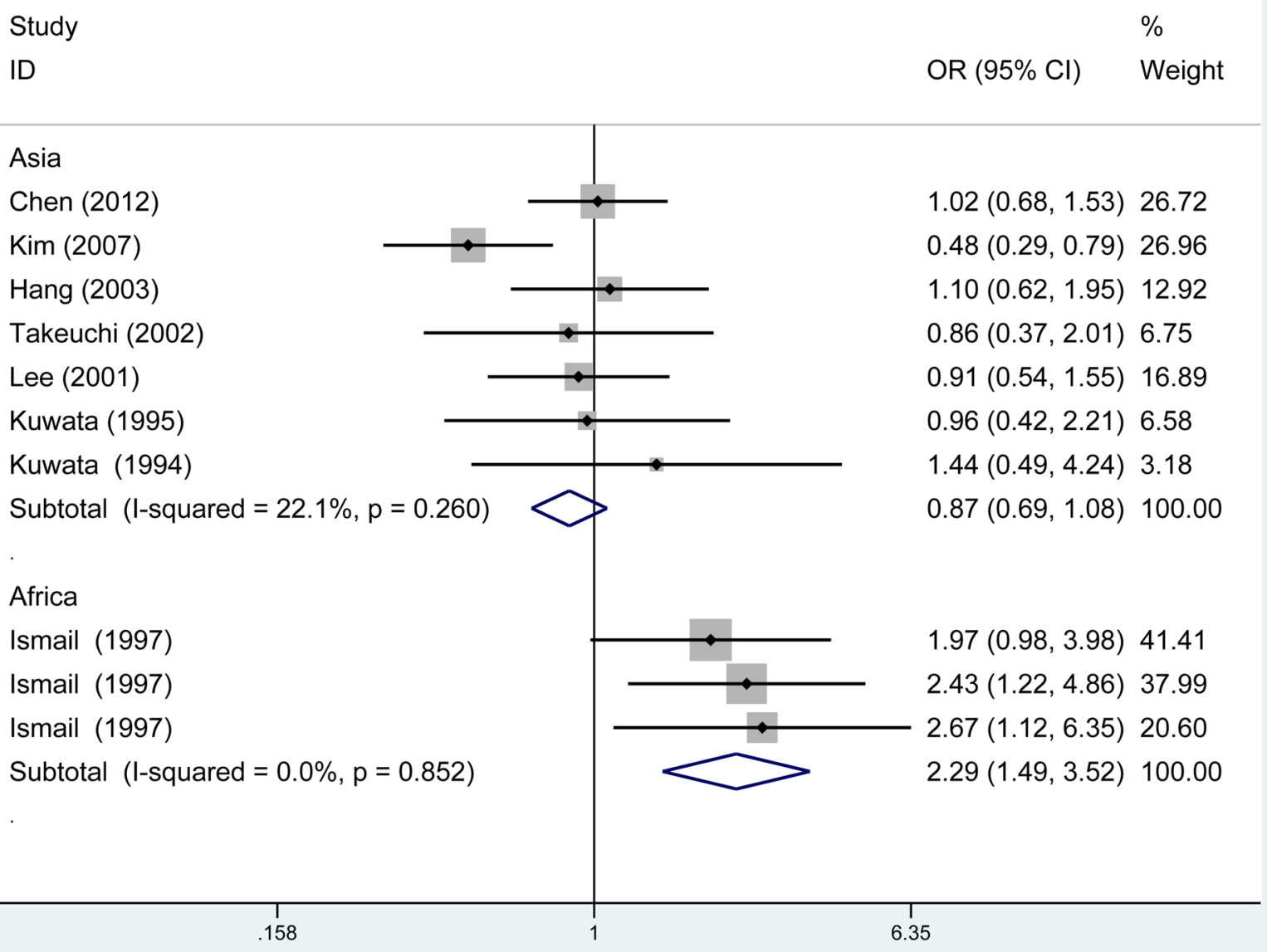

Figure 2: Subgroup analysis of the relationship between TAP1 rs1057141 polymorphism and atopic diseases stratified by the ethnicity of study population. $\mathrm{I}^{2}$ and $\mathrm{P}_{\text {heterogeneity }}$ for the outcomes of the allelic comparison in $\mathrm{Asians}\left(\mathrm{I}^{2}=22.1 \%, P_{\mathrm{h}}=0.260\right)$ and Africans $\left(\mathrm{I}^{2}=0, P_{\mathrm{h}}=0.852\right)$. 
Table 2: Analysis of the effect of TAP1 rs1057141 on the risk of atopic diseases

\begin{tabular}{|c|c|c|c|c|c|c|c|c|c|c|}
\hline \multirow[b]{2}{*}{ Genetic model } & \multirow[b]{2}{*}{ Population } & \multirow[b]{2}{*}{ Studies } & \multicolumn{3}{|c|}{$\begin{array}{r}\text { Statistics } \\
\end{array}$} & \multicolumn{3}{|c|}{ Heterogeneity } & \multicolumn{2}{|c|}{ Publication bias } \\
\hline & & & OR(95\%CI $)$ & $\mathbf{Z}$ & $P$ & $P_{\text {heterogeneity }}$ & $\mathrm{I}^{2(\%)}$ & Model & $\boldsymbol{P}_{\text {begg }}$ & $P_{\text {egger }}$ \\
\hline \multirow[t]{6}{*}{ Allele (G vs. A) } & Overall & 10 & $1.16(0.83-1.63)$ & 0.88 & 0.378 & 0.005 & 62.1 & $\mathrm{R}$ & 0.283 & 0.160 \\
\hline & $\mathrm{AR}$ & 4 & $0.98(0.52-1.86)$ & 0.05 & 0.963 & 0.002 & 79.4 & $\mathrm{R}$ & 1.000 & 0.699 \\
\hline & AA & 2 & $1.38(0.88-2.16)$ & 1.41 & 0.158 & 0.204 & 38.0 & $\mathrm{~F}$ & 1.000 & NA \\
\hline & $\mathrm{AD}$ & 4 & $1.26(0.77-2.06)$ & 0.92 & 0.359 & 0.198 & 35.7 & $\mathrm{~F}$ & 0.308 & 0.388 \\
\hline & Asian & 7 & $0.87(0.69-1.08)$ & 1.29 & 0.196 & 0.260 & 22.1 & $\mathrm{~F}$ & 0.764 & 0.591 \\
\hline & African & 3 & $2.29(1.49-3.52)$ & 3.79 & 0.000 & 0.852 & 0.0 & $\mathrm{~F}$ & 1.000 & 0.565 \\
\hline \multirow[t]{6}{*}{ Dominant (GG+AG vs. AA) } & Overall & 10 & $1.22(0.78-1.90)$ & 0.87 & 0.386 & 0.000 & 70.7 & $\mathrm{R}$ & 0.283 & 0.185 \\
\hline & $\mathrm{AR}$ & 4 & $1.01(0.41-2.50)$ & 0.02 & 0.986 & 0.000 & 86.7 & $\mathrm{R}$ & 1.000 & 0.697 \\
\hline & $\mathrm{AA}$ & 2 & $1.60(0.89-2.88)$ & 1.57 & 0.116 & 0.273 & 16.6 & $\mathrm{~F}$ & 1.000 & NA \\
\hline & $\mathrm{AD}$ & 4 & $1.23(0.76-1.98)$ & 0.83 & 0.407 & 0.325 & 13.5 & $\mathrm{~F}$ & 0.308 & 0.254 \\
\hline & Asian & 7 & $0.86(0.58-1.28)$ & 0.73 & 0.466 & 0.051 & 52.1 & $\mathrm{R}$ & 1.000 & 0.590 \\
\hline & African & 3 & $2.79(1.70-4.59)$ & 4.04 & 0.000 & 0.721 & 0.0 & $\mathrm{~F}$ & 1.000 & 0.937 \\
\hline \multirow[t]{6}{*}{ Recessive (GG vs. AG+AA) } & Overall & 10 & $1.03(0.57-1.86)$ & 0.09 & 0.926 & 0.814 & 0.0 & $\mathrm{~F}$ & 0.466 & 0.378 \\
\hline & $\mathrm{AR}$ & 4 & $0.87(0.34-2.26)$ & 0.28 & 0.778 & 0.617 & 0.0 & $\mathrm{~F}$ & 1.000 & 0.578 \\
\hline & AA & 2 & $1.02(0.31-3.32)$ & 0.03 & 0.972 & 0.526 & 0.0 & $\mathrm{~F}$ & 1.000 & NA \\
\hline & $\mathrm{AD}$ & 4 & $1.24(0.47-3.28)$ & 0.43 & 0.667 & 0.391 & 0.0 & $\mathrm{~F}$ & 1.000 & 0.815 \\
\hline & Asian & 7 & $0.91(0.46-1.78)$ & 0.29 & 0.773 & 0.909 & 0.0 & $\mathrm{~F}$ & 0.260 & 0.187 \\
\hline & African & 3 & $1.58(0.47-5.31)$ & 0.74 & 0.457 & 0.383 & 0.0 & $\mathrm{~F}$ & 1.000 & 0.339 \\
\hline \multirow[t]{6}{*}{ Homozygous (GG vs. AA) } & Overall & 10 & $1.08(0.59-1.96)$ & 0.24 & 0.812 & 0.834 & 0.0 & $\mathrm{~F}$ & 0.602 & 0.352 \\
\hline & AR & 4 & $0.88(0.33-2.35)$ & 0.25 & 0.801 & 0.809 & 0.0 & $\mathrm{~F}$ & 0.734 & 0.474 \\
\hline & AA & 2 & $1.17(0.35-3.86)$ & 0.25 & 0.800 & 0.483 & 0.0 & $\mathrm{~F}$ & 1.000 & NA \\
\hline & $\mathrm{AD}$ & 4 & $1.25(0.47-3.34)$ & 0.45 & 0.655 & 0.303 & 16.4 & $\mathrm{~F}$ & 1.000 & 0.783 \\
\hline & Asian & 7 & $0.89(0.45-1.78)$ & 0.32 & 0.750 & 0.970 & 0.0 & $\mathrm{~F}$ & 0.133 & 0.196 \\
\hline & African & 3 & $2.07(0.60-1.96)$ & 1.16 & 0.247 & 0.452 & 0.0 & $\mathrm{~F}$ & 1.000 & 0.385 \\
\hline \multirow[t]{6}{*}{ Heterozygous (AG vs. AA) } & Overall & 10 & $0.76(0.76-1.97)$ & 0.85 & 0.398 & 0.000 & 72.2 & $\mathrm{R}$ & 0.283 & 0.213 \\
\hline & AR & 4 & $1.03(0.38-2.80)$ & 0.06 & 0.949 & 0.000 & 88.4 & $\mathrm{R}$ & 1.000 & 0.696 \\
\hline & AA & 2 & $1.65(0.94-2.89)$ & 1.75 & 0.080 & 0.338 & 0.0 & $\mathrm{~F}$ & 1.000 & NA \\
\hline & $\mathrm{AD}$ & 4 & $1.17(0.74-1.85)$ & 0.68 & 0.500 & 0.514 & 0.0 & $\mathrm{~F}$ & 0.308 & 0.148 \\
\hline & Asian & 7 & $0.87(0.56-1.36)$ & 0.60 & 0.549 & 0.025 & 58.4 & $\mathrm{R}$ & 1.000 & 0.582 \\
\hline & African & 3 & $2.88(1.72-4.85)$ & 4.00 & 0.000 & 0.565 & 0.0 & $\mathrm{~F}$ & 1.000 & 0.696 \\
\hline
\end{tabular}

$\mathrm{AD}$, atopic dermatitis; $\mathrm{AR}$, allergic rhinitis; AA, asthma; OR, odds ratio; CI, confidence interval; NA, not applicable; Bold values are statistically significant $(P<0.05)$.

\section{Meta-analysis results}

\section{TAP1 rs1057141 polymorphism and atopic diseases susceptibility}

The summary of meta-analysis for TAP1 rs1057141 polymorphism with atopic diseases was demonstrated in Table 2. Overall, significant association was not identified in any genetic model. Besides, it was revealed that significant heterogeneity was present in allelic, dominant, heterozygous genetic models (Table 2). Interestingly, when stratified by ethnicity, heterogeneity disappeared in Asians $\left(\mathrm{I}^{2}=22.1 \%, P_{\mathrm{h}}=0.260\right)$ and Africans $\left(\mathrm{I}^{2}=0 \%, P_{\mathrm{h}}=0.852\right)$ in allelic comparisons (Figure 2). In African population, increased risk of atopic disease was found in the allelic (odds ratio $(\mathrm{OR})=2.29,95 \% \mathrm{CI}$ (confidence interval) 1.49 $3.52, P<0.001)$, dominant $(\mathrm{OR}=2.79,95 \%$ CI 1.70-4.59, $P<0.001)$ and heterozygous (OR $=2.88,95 \%$ CI 1.72 $4.85, P<0.001$ ) model (Table 2). Additionally, subgroup analysis was conducted by dividing the whole population into three subgroups by atopic types, which include AA, $\mathrm{AD}, \mathrm{AR}$ groups. No significant association was identified in any genetic models (Table 2).

TAP1 rs1135216 polymorphism and atopic diseases susceptibility

The results of associations between rs 1135216 polymorphism and the risk of atopic diseases were shown in Table 3. A significant increase in the risk of atopic diseases was observed in recessive comparison (OR $=4.71,95 \%$ CI $2.75-8.06, P<0.001)$ and homozygote comparison $(\mathrm{OR}=3.68,95 \% \mathrm{CI} 1.53-8.89, P<0.001)$ in overall populations (Figure 3).

From subgroup analysis by ethnicity, it demonstrated a significant association of TAP1 rs 1135216 polymorphism and atopic diseases in Africans in all five genetic models ( $\mathrm{G}$ versus $\mathrm{A}: \mathrm{OR}=5.33,95 \% \mathrm{CI} 3.67-7.75, P<0.001 ; \mathrm{AG} /$ GG versus $\mathrm{AA}: \mathrm{OR}=4.76,95 \% \mathrm{CI} 2.93-7.73, P<0.001$; GG versus AG/AA: $\mathrm{OR}=12.15,95 \%$ CI 5.54-26.62, $P<$ 0.001 ; GG versus AA: $\mathrm{OR}=15.85,95 \% \mathrm{CI} 6.96-36.08, P$ $<0.001$; AG versus AA: OR $=2.54,95 \%$ CI $1.44-4.46, P$ $=0.001$ ) but not in Asians (Table 3). Interestingly, when stratified by ethnicity, heterogeneity disappeared in Asians $\left(\mathrm{I}^{2}=0 \%, P_{\mathrm{h}}=0.995\right)$ and Africans $\left(\mathrm{I}^{2}=0 \%, P_{\mathrm{h}}=0.532\right)$ in homozygous comparison (Figure 4). Subgroup analysis 
Table 3: Analysis of the effect of TAP1 rs1135216 on the risk of atopic diseases

\begin{tabular}{|c|c|c|c|c|c|c|c|c|c|c|}
\hline \multirow[t]{2}{*}{ Genetic model } & \multirow[t]{2}{*}{ Population } & \multirow[t]{2}{*}{ Studies } & \multicolumn{3}{|c|}{ Statistics } & \multicolumn{3}{|c|}{ Heterogeneity } & \multicolumn{2}{|c|}{ Publication bias } \\
\hline & & & OR(95\%CI) & $\mathbf{Z}$ & $P$ & $\boldsymbol{P}_{\text {heterogeneity }}$ & $I^{2}(\%)$ & Model & $\boldsymbol{P}_{\text {begg }}$ & $\boldsymbol{P}_{\text {egger }}$ \\
\hline \multirow[t]{6}{*}{ Allele (G vs. A) } & Overall & 10 & $1.52(0.83-2.78)$ & 1.36 & 0.174 & 0.000 & 88.2 & $\mathrm{R}$ & 1.000 & 0.819 \\
\hline & $\mathrm{AR}$ & 4 & $1.22(0.54-2.74)$ & 0.49 & 0.628 & 0.000 & 88.8 & $\mathrm{R}$ & 1.000 & 0.642 \\
\hline & AA & 2 & $4.92(1.90-12.69)$ & 3.29 & 0.001 & 0.077 & 68.1 & $\mathrm{R}$ & 1.000 & NA \\
\hline & $\mathrm{AD}$ & 4 & $1.07(0.42-2.70)$ & 0.14 & 0.885 & 0.002 & 79.9 & $\mathrm{R}$ & 0.734 & 0.604 \\
\hline & Asian & 7 & $0.91(0.62-1.35)$ & 0.46 & 0.648 & 0.027 & 57.8 & $\mathrm{R}$ & 0.764 & 0.894 \\
\hline & African & 3 & $5.33(3.67-7.75)$ & 8.77 & 0.000 & 0.318 & 12.6 & $\mathrm{~F}$ & 0.296 & 0.535 \\
\hline \multirow[t]{6}{*}{ Dominant (GG+AG vs. AA) } & Overall & 10 & $1.39(0.76-2.55)$ & 1.07 & 0.284 & 0.000 & 83.8 & $\mathrm{R}$ & 1.000 & 0.519 \\
\hline & AR & 4 & $1.08(0.45-2.59)$ & 0.18 & 0.859 & 0.000 & 86.6 & $\mathrm{R}$ & 1.000 & 0.617 \\
\hline & AA & 2 & $4.10(2.24-7.52)$ & 4.56 & 0.000 & 0.489 & 0.0 & $\mathrm{~F}$ & 1.000 & NA \\
\hline & $\mathrm{AD}$ & 4 & $1.04(0.36-3.01)$ & 0.08 & 0.937 & 0.003 & 79.0 & $\mathrm{R}$ & 1.000 & 0.800 \\
\hline & Asian & 7 & $0.84(0.51-1.39)$ & 0.68 & 0.500 & 0.006 & 67.1 & $\mathrm{R}$ & 0.764 & 0.881 \\
\hline & African & 3 & $4.76(2.93-7.73)$ & 6.29 & 0.000 & 0.979 & 0.0 & $\mathrm{~F}$ & 1.000 & 0.832 \\
\hline \multirow[t]{6}{*}{ Recessive (GG vs. AG+AA) } & Overall & 10 & $4.71(2.75-8.06)$ & 5.65 & 0.000 & 0.078 & 43.5 & $\mathrm{~F}$ & 0.029 & 0.016 \\
\hline & AR & 4 & $3.46(1.51-7.93)$ & 2.94 & 0.003 & 0.381 & 2.3 & $\mathrm{~F}$ & 0.734 & 0.252 \\
\hline & $\mathrm{AA}$ & 2 & $7.54(0.41-137.37)$ & 1.36 & 0.173 & 0.084 & 66.5 & $\mathrm{R}$ & 1.000 & NA \\
\hline & $\mathrm{AD}$ & 4 & $2.02(0.70-5.81)$ & 1.31 & 0.191 & 0.434 & 0.0 & $\mathrm{~F}$ & 0.296 & 0.372 \\
\hline & Asian & 7 & $1.55(0.67-3.56)$ & 1.03 & 0.304 & 0.987 & 0.0 & $\mathrm{~F}$ & 0.133 & 0.291 \\
\hline & African & 3 & $12.15(5.54-26.62)$ & 6.24 & 0.000 & 0.267 & 24.3 & $\mathrm{~F}$ & 0.296 & 0.386 \\
\hline \multirow[t]{6}{*}{ Homozygous (GG vs. AA) } & Overall & 10 & $3.68(1.53-8.89)$ & 2.90 & 0.004 & 0.038 & 50.9 & $\mathrm{R}$ & 0.251 & 0.026 \\
\hline & $\mathrm{AR}$ & 4 & $3.52(1.53-8.10)$ & 2.96 & 0.003 & 0.163 & 41.4 & $\mathrm{~F}$ & 1.000 & 0.269 \\
\hline & AA & 2 & $9.03(0.63-130.17)$ & 1.62 & 0.106 & 0.110 & 60.8 & $\mathrm{R}$ & 1.000 & NA \\
\hline & $\mathrm{AD}$ & 4 & $2.28(0.79-6.60)$ & 1.51 & 0.130 & 0.240 & 29.8 & $\mathrm{~F}$ & 1.000 & 0.526 \\
\hline & Asian & 7 & $1.43(0.62-3.32)$ & 0.84 & 0.400 & 0.995 & 0.0 & $\mathrm{~F}$ & 0.707 & 0.534 \\
\hline & African & 3 & $15.85(6.96-36.08)$ & 6.58 & 0.000 & 0.532 & 0.0 & $\mathrm{~F}$ & 0.296 & 0.375 \\
\hline \multirow[t]{6}{*}{ Heterozygous (AG vs. AA) } & Overall & 10 & $1.11(0.66-1.85)$ & 0.38 & 0.702 & 0.000 & 73.9 & $\mathrm{R}$ & 0.474 & 0.486 \\
\hline & AR & 4 & $0.92(0.43-1.97)$ & 0.21 & 0.837 & 0.002 & 80.4 & $\mathrm{R}$ & 0.734 & 0.670 \\
\hline & AA & 2 & $2.18(1.11-4.31)$ & 2.25 & 0.024 & 0.190 & 41.8 & $\mathrm{~F}$ & 1.000 & NA \\
\hline & $\mathrm{AD}$ & 4 & $1.00(0.36-2.80)$ & 0.01 & 0.996 & 0.006 & 75.7 & $\mathrm{R}$ & 1.000 & 0.845 \\
\hline & Asian & 7 & $0.81(0.48-1.36)$ & 0.80 & 0.425 & 0.004 & 68.3 & $\mathrm{R}$ & 0.764 & 0.899 \\
\hline & African & 3 & $2.54(1.44-4.46)$ & 3.24 & 0.001 & 0.235 & 30.9 & $\mathrm{~F}$ & 1.000 & 0.876 \\
\hline
\end{tabular}

$\mathrm{AD}$, atopic dermatitis; $\mathrm{AR}$, allergic rhinitis; $\mathrm{AA}$, asthma; OR, odds ratio; $\mathrm{CI}$, confidence interval; NA, not applicable; Bold values are statistically significant $(P<0.05)$.

by atopic types indicated a significant association in AA in the allele $(\mathrm{OR}=4.92,95 \% \mathrm{CI} 1.90-12.69, P=0.001)$, dominant $(\mathrm{OR}=4.10,95 \% \mathrm{CI} 2.24-7.52, P<0.001)$ and heterozygous $(\mathrm{OR}=2.18,95 \% \mathrm{CI} 1.11-4.31, P=0.024)$ models and $\mathrm{AR}$ in the recessive $(\mathrm{OR}=3.46,95 \% \mathrm{CI} 1.51$ 7.93, $P=0.003$ ) and homozygous (OR $=3.52,95 \% \mathrm{CI}$ 1.53-8.10, $P=0.003$ ) models (Table 3 ).

\section{Publication bias and sensitivity analysis}

With the use of Begg's funnel plot and quantitative Egger's test, publication bias was assessed and no obvious publication bias was found for the association between rs1057141 and atopic diseases risk (Table 2). Symmetrical funnel plots were obtained in all the genetic models. As for rs1135216, quantitative Egger's test of the included studies showed potential publication bias in recessive comparison $\left(P_{\text {egger }}=0.016\right)$ and homozygote comparison $\left(P_{\text {egger }}=0.026\right)$ (Table 3$)$. However, when stratified by ethnicity, such publication bias disappeared in both Asian (recessive: $P_{\text {egger }}=0.291$; homozygous: $P_{\text {egger }}=0.534$ ) and African (recessive: $P_{\text {egger }}=0.386$; homozygous: $P_{\text {egger }}=$ 0.375 ) groups (Table 3). Result from trim-and-fill analysis, which was to investigate the effect of missing trials, showed "no trimming performed; data unchanged". In addition, sensitivity analysis which evaluated the impact of individual study on overall ORs showed that exclusion of any study made no significant difference (Figure 5).

\section{DISCUSSION}

Our study for the first time assessed the relationships between TAP1 rs1057141 and rs1135216 polymorphism and atopic diseases risk through quantitative meta-analysis of the published case-control studies. The results showed that rs 1135216 polymorphism might have a significant association with atopic diseases risk.

Allergic diseases are frequent chronic diseases and recognized as a group of immune-mediated disorders [17]. Progress of allergic symptoms could start with atopic dermatitis that could be accompanied with sensitization to aeroallergen during early childhood, followed by asthma and allergic rhinitis during later childhood or adult life [2, 18]. Epidemiological studies have demonstrated the atopic diseases have developed as an epidemic disease through the last decades. However, pathogenesis, natural course and the underlying mechanisms of atopic diseases is still 
unclear. [19]. Etiology of AD includes alterations in skin barrier function, immune dysregulation and exposure to environmental, which could ultimately lead to the classic skin manifestation of AD [20]. Environmental allergens could cross a dysfunctional skin barrier, which will activate immune system and elicit AD symptoms.
Antigen presentation, which is required for priming the immunologic response to external antigen is regulated by HLA molecules. HLA are encoded within MHC located on chromosome 6 [21] which hosts hundreds of genes that code for cell-surface antigens and therefore affect immune system function [21].

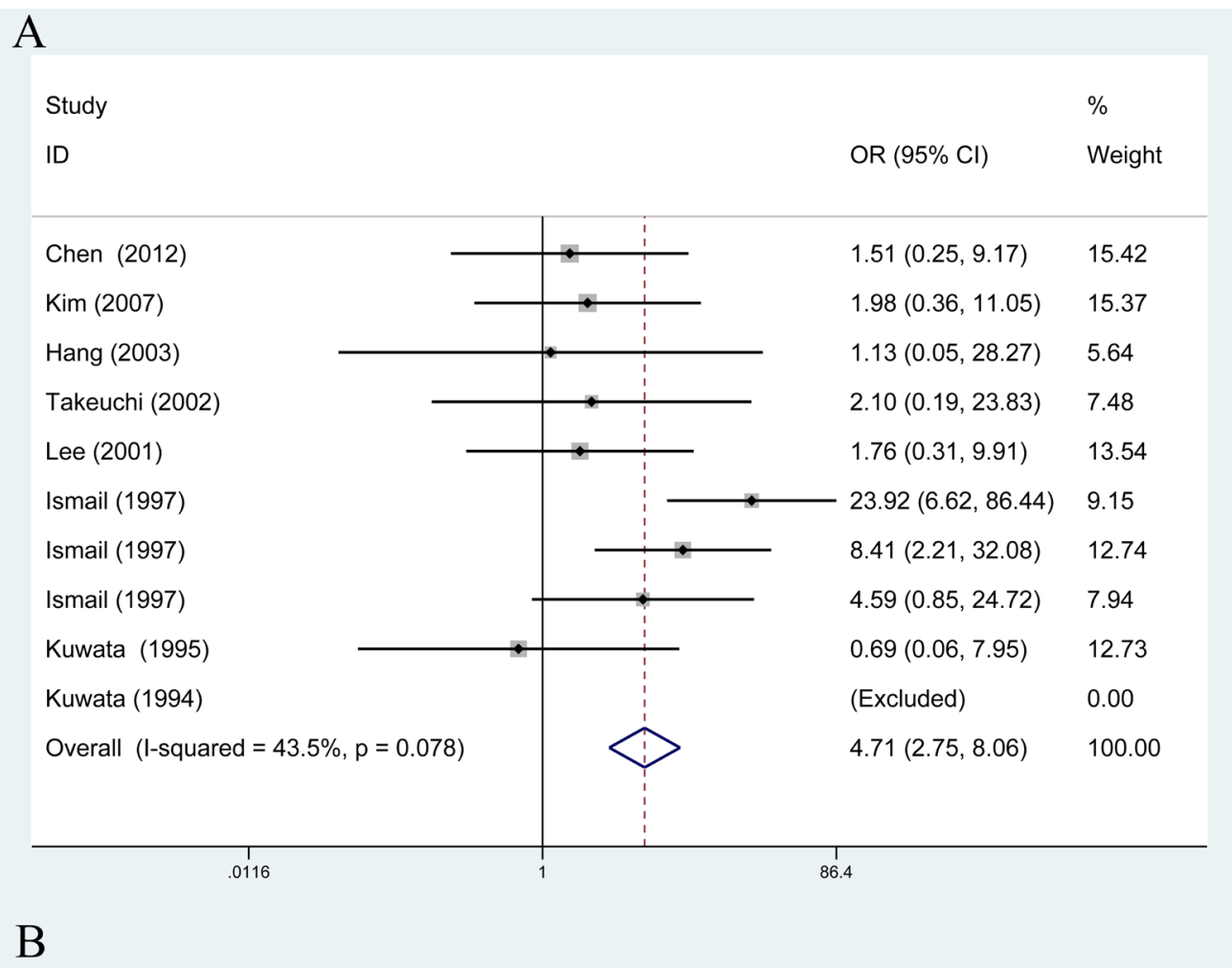

B

Study

ID
$\%$

OR $(95 \% \mathrm{Cl}) \quad$ Weight

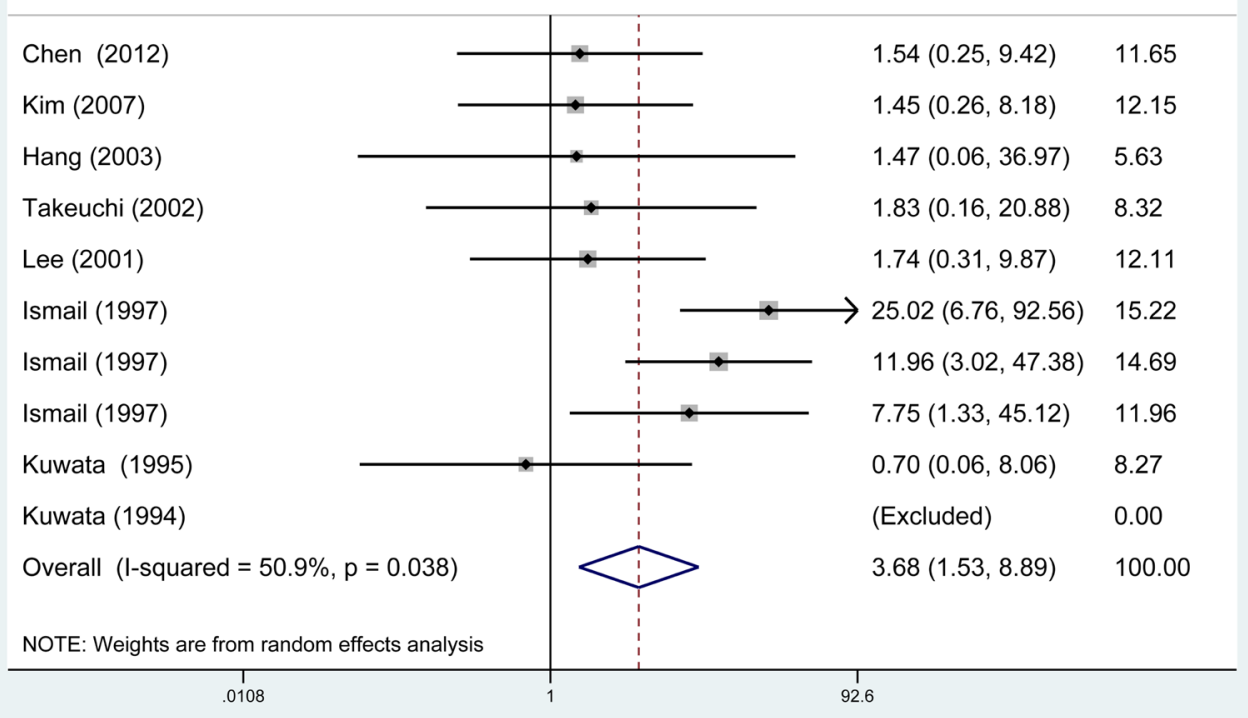

Figure 3: Overall meta-analysis of the relationship between TAP1 rs1135216 polymorphism and atopic diseases risk. A. Recessive model (GG vs. AA+AG); B. Homozygote model (GG vs. AA). 
TAP gene is located within the MHC class II region of chromosome 6 between the HLA-DP and HLA-DQ loci. The TAP protein is critical for the processing and presentation of intracellular antigens [22]. Though most studies on the influences of TAP1 on atopic diseases susceptibility reported consistent findings, contradictory results have been observed from replicating studies of different ethnic populations. TAP1 rs1135216, as a common TAP1 gene polymorphism, is associated with atopic diseases $[5-7,9,10]$. Substitution of the $637^{\text {th }}$ amino acid aspartate by glycine in TAP 1 protein resulted from the replacement of the $2120^{\text {th }}$ base adenine by guanine in TAP1 rs1135215 compared with that of TAP1 gene seems responsible for the increased atopic diseases risk. From the 10 studies analyzing rs1135216 in exon 10, 4 studies found significant association between rs1135216 and atopic diseases, which was absent from the other 6 studies.

The present meta-analysis systematically evaluated the association between rs1057141 and rs1135216 polymorphisms and atopic diseases susceptibility. Positive association between TAP1 rs1135216 polymorphism and increased atopic diseases risk was observed and patients with the GG genotype may be susceptible to atopic diseases. High heterogeneities were observed in the allele, dominant and heterozygous models. However, when stratified by ethnicity, heterogeneity disappeared in Asians and Africans. Difference between Asians and Africans indicated that rs1135216 polymorphism might be ethnicity-specific. Sub-population analysis revealed association between different genotypes and Africa population. The atopic diseases risk increased significantly in Africa populations using allelic, dominant, recessive, homozygous and heterozygous genetic models. As to rs1057141, increased risk of atopic disease in the allelic, dominant and heterozygous model was found in African population. Additionally, with sensitivity analysis

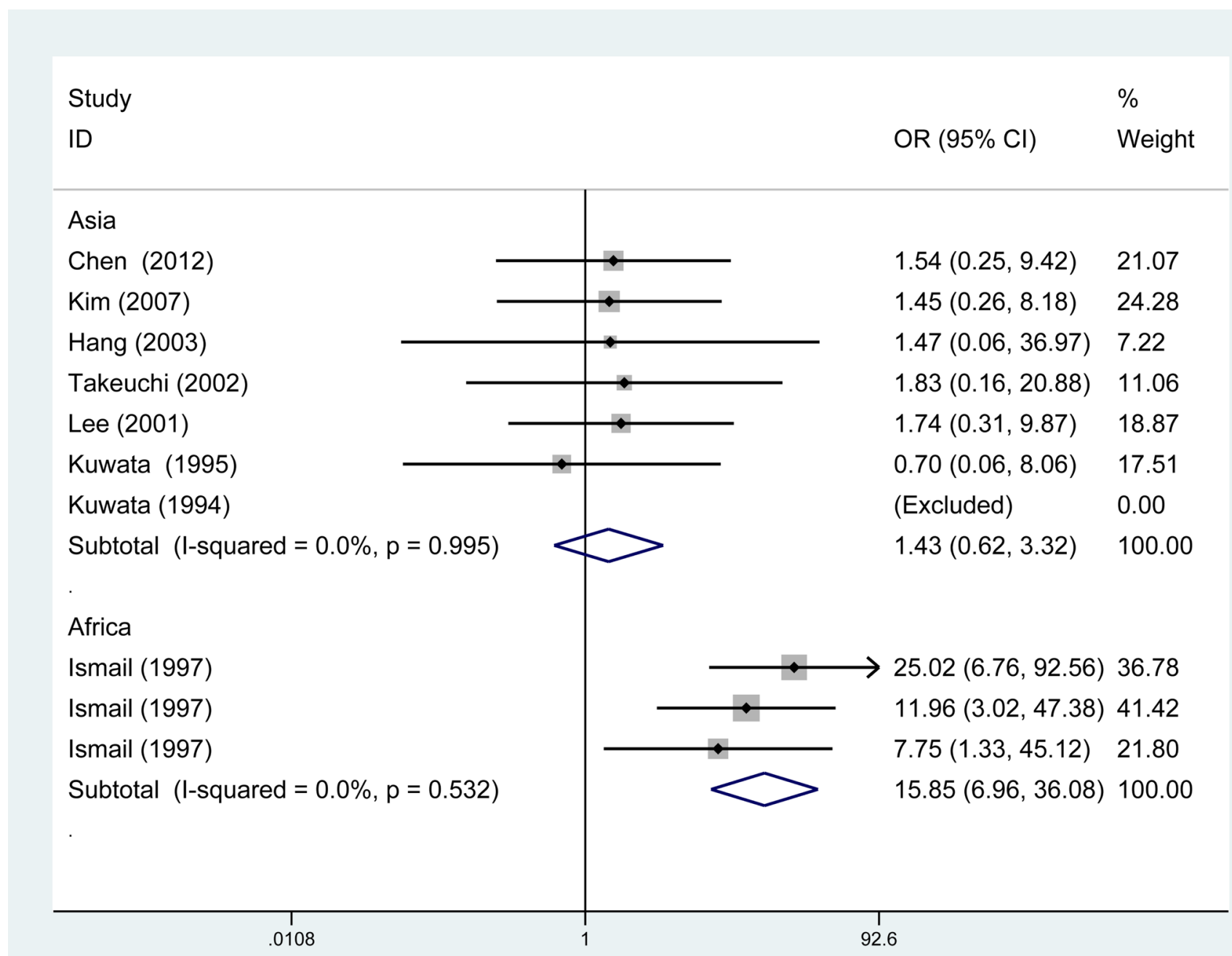

Figure 4: Subgroup analysis of the relationship between TAP1 rs1135216 polymorphism and atopic diseases stratified by the ethnicity of study population. $\mathrm{I}^{2}$ and Pheterogeneity for the outcomes of the homozygous comparison in Asians $\left(\mathrm{I}^{2}=0 \%\right.$, $\left.P_{\mathrm{h}}=0.995\right)$ and Africans $\left(\mathrm{I}^{2}=0 \%, P_{\mathrm{h}}=0.532\right)$. 
indicating our data stable and robust, our results may assist the establishment of personal therapy in atopic diseases.

A few limitations presented in this meta-analysis should be considered if the data are to be used further. First, different research methods may increase the heterogeneity of these studies. Second, only Asian and African populations are included in the current analysis, and therefore studies on ethnicities such as Caucasians are needed for further investigation. Additionally, the heterogeneity present in some genetic models also posed as limitation of this study. To overcome the limitation present in this study, large-scale studies are required to validate the significance of our conclusions.

In summary, this meta-analysis supported evidence that rs1135216 polymorphism may confer susceptibility to atopic diseases in the overall population and especially among Africans.

\section{MATERIALS AND METHODS}

Conduction of meta-analysis was based on the PRISMA guidelines [23].
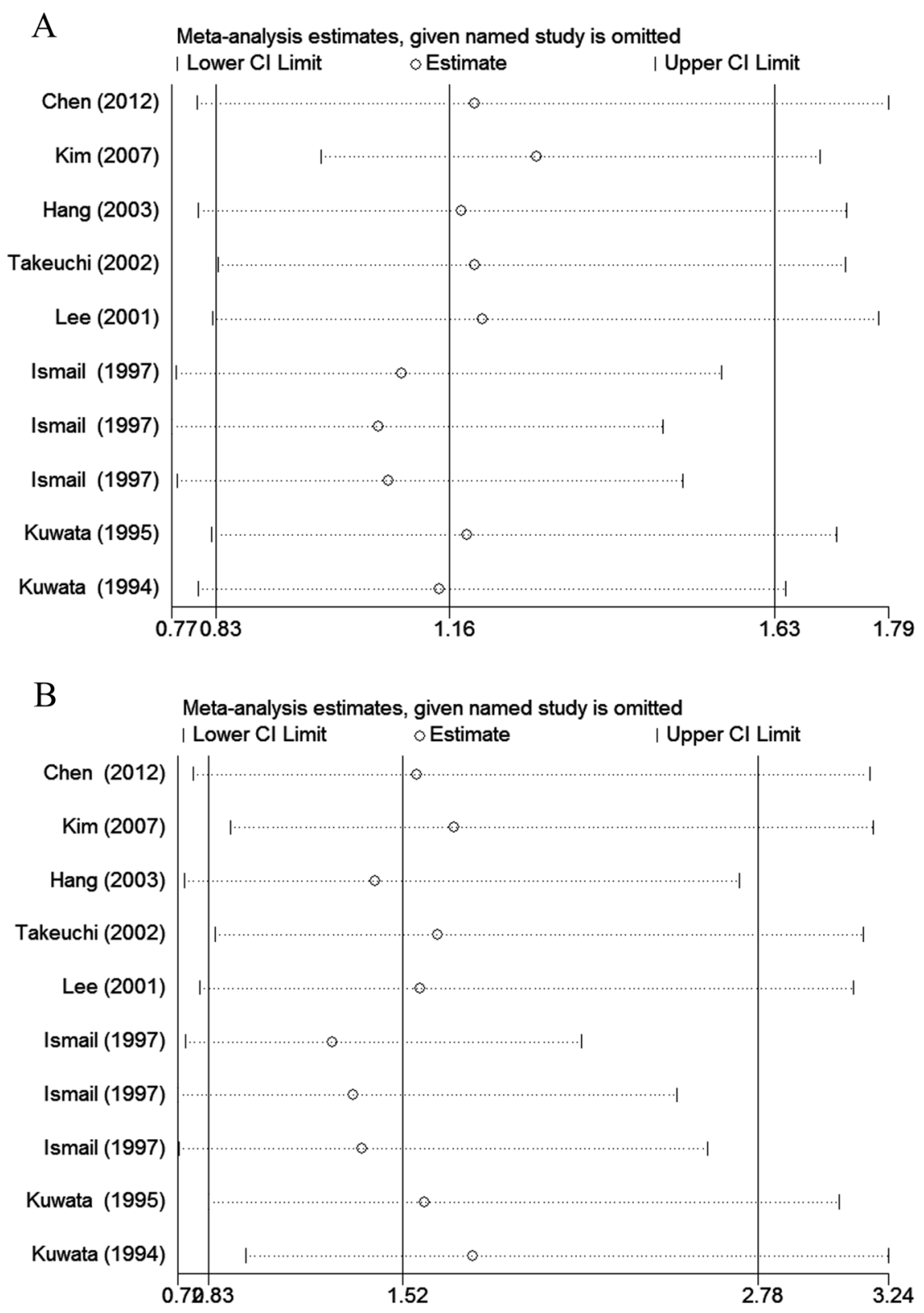

Figure 5: The impact of individual studies on the overall OR in allele model (G vs. A). A. rs1057141; B. rs1135216. 


\section{Search strategy and selection criteria}

Databases including PubMed, EMBASE and Web of Science (last updated on July, 2017) were used as the source for identifying published investigations on the relationship between TAP1 polymorphism and atopic risk. Time was not limited for the search of the eligible literature. Keywords used for searching the literature include: 'transporter associated with antigen processing 1','TAP1', 'polymorphism', 'variant', 'genotype', 'allele', 'dermatitis', 'rhinitis', and 'asthma'. Besides, to identify further eligible articles, reference lists of all relevant articles were reviewed manually.

Criteria used for selection of eligible studies include: (1) being a unrelated case-control design study; (2) include investigation of the relationship between TAP1 polymorphisms and atopic dermatitis, allergic rhinitis, and/or asthma; (3) including sufficient data to calculate the pooled ORs with $95 \% \mathrm{CI}$ [24].

\section{Data extraction and quality assessment}

The types of data extracted from the included studies are: first author, publication year, country, ethnicity, genotype methods, the number of cases and controls, distributions of genotypes and alleles in atopic patients and control subjects, and the probability value of HWE in control group. Data extraction was carried out independently by Liu and Chen who also performed study quality assessment. Disagreements were solved by discussion.

Scoring system was established by incorporating traditional epidemiological considerations together with atopic genetic issues recommended by Thakkinstian to assess study quality [25]. Six perspectives were evaluated to assess the study quality: representativeness of samples, ascertainment of samples, genotyping methods, association assessment, response rate and HWE of the control groups (Supplementary Table 1) [26]. The scores were set ranging from 0 (worst) to 15 (best). Any disagreement aroused between the previous mentioned two researchers was adjudicated by a third researcher (Qi). Any study with a quality score of $\leq 4$ was considered to be low quality and excluded for further analysis [27].

\section{Statistical analysis}

Statistical analysis was performed with StataMP 14 (StataCorp, College Station, TX). Five genetic models including the allelic ( $\mathrm{G}$ versus $\mathrm{A})$, dominant $(\mathrm{AG}+\mathrm{GG}$ versus $\mathrm{AA}$ ), recessive ( $\mathrm{GG}$ versus $\mathrm{AG}+\mathrm{AA}$ ), homozygous (GG versus AA) and heterozygous (AG versus AA) models were adopted [28]. The relationships between TAP1 gene polymorphism and atopic diseases amongst different models were compared using OR and its corresponding 95\% CI. Chi-squared-based Q-test was employed to evaluate the heterogeneity between the individual studies with $P<0.1$ considered as significant. In the presence of heterogeneity among individual studies, estimation of pooled OR was conducted utilizing a random-effect model. Otherwise, a fixed-effect model was applied. The pooled OR was determined by Z-test, and OR with $P<$ 0.05 was considered as significant [29]. To confirm the validity of HWE, Genotype distributions in the control subjects were tested with $\chi^{2}$ test, and significance was set at $P<0.05$. Subgroup analysis by ethnicity and atopic types was performed to investigate possible causes of heterogeneity. Influence of individual study on the overall analysis outcome was assessed by sensitivity analysis, in which the results by stability was tested by excluding each study in sequence to examine their impact on the test of heterogeneity. To determine whether there existed publication bias, Funnel plots, Begg's test and Egger's test were applied. In the case of presence of publication bias, the trim and fill approach was applied to adjust the metaanalysis results by imputing data from presumed missing studies [30].

\section{CONFLICTS OF INTEREST}

All authors declare no conflicts of interest.

\section{REFERENCES}

1. Settipane RA, Charnock DR. Epidemiology of rhinitis: allergic and nonallergic. Clin Allergy Immunol. 2007; 19: 23-34.

2. Spergel JM. From atopic dermatitis to asthma: the atopic march. Ann Allergy Asthma Immunol. 2010; 105: 99-106.

3. Thomsen SF. Epidemiology and natural history of atopic diseases. Eur Clin Respir J. 2015; 2: 1-6.

4. Kim HK, Lee H, Lew BL, Sim WY, Kim YO, Lee SW, Lee S, Cho IK, Kwon JT, Kim HJ. Association between TAP1 gene polymorphisms and alopecia areata in a Korean population. Genet Mol Res. 2015; 14: 18820-7.

5. Chen Q, Liu Z, Zhang H. [Relationship between rs1057141 and rs1135216 polymorphisms of TAP1 gene and allergic rhinitis in Xinjiang Han people]. [Article in Chinese]. Lin Chung Er Bi Yan Hou Tou Jing Wai Ke Za Zhi. 2012; 26:917-20, 925.

6. Hang LW, Hsia TC, Chen WC, Chen HY, Tsai FJ. TAP1 gene AccI polymorphism is associated with atopic bronchial asthma. J Clin Lab Anal. 2003; 17: 57-60.

7. Ismail A, Bousaffara R, Kaziz J, Zili J, el Kamel A, Tahar Sfar M, Remadi S, Chouchane L. Polymorphism in transporter antigen peptides gene (TAP1) associated with atopy in Tunisians. J Allergy Clin Immunol. 1997; 99: 21623.

8. Izakovicova Holla L, Vasku A, Izakovic V, Znojil V. The 
interaction of the polymorphisms in transporter of antigen peptides (TAP) and lymphotoxin alpha (LT-alpha) genes and atopic diseases in the Czech population. Clin Exp Allergy. 2001; 31: 1418-23.

9. Kim KR, Cho SH, Choi SJ, Jeong JH, Lee SH, Park CW, Tae K. TAP1 and TAP2 gene polymorphisms in Korean patients with allergic rhinitis. J Korean Med Sci. 2007; 22: 825-31.

10. Kuwata S, Yanagisawa M, Saeki H, Nakagawa H, Etoh T, Tokunaga K, Juji T, Shibata Y. Polymorphisms of transporter associated with antigen processing genes in atopic dermatitis. J Allergy Clin Immunol. 1994; 94: 56574.

11. Kuwata S, Yanagisawa M, Saeki H, Nakagawa H, Etoh T, Tokunaga K, Juji T, Shibata Y. Lack of primary association between transporter associated with antigen processing genes and atopic dermatitis. J Allergy Clin Immunol. 1995; 96: 1051-60.

12. Lee HJ, Ha SJ, Han H, Kim JW. Distribution of HLA-A, $\mathrm{B}$ alleles and polymorphisms of TAP and LMP genes in Korean patients with atopic dermatitis. Clin Exp Allergy. 2001; 31: 1867-74.

13. Takeuchi K, Abe S, Masuda S, Yuta A, Majima Y, Sakakura Y. Lack of association between gene polymorphism of transporters associated with antigen processing and allergic rhinitis in a Japanese population. Ann Otol Rhinol Laryngol. 2002; 111: 460-3.

14. Yilmaz I, Atac FB, Erkan AN, Verdi H, Cagici CA, Aslan $\mathrm{S}$, Sahin FI, Ozluoglu LN. No difference in polymorphism frequency in a Turkish population with allergic rhinitis. Acta Otolaryngol. 2006; 126: 1110-1.

15. Lin $\mathrm{HC}, \mathrm{Su} \mathrm{BH}$, Hsu CM, Chou IC, Wu KH, Lin HC, Tsai FJ, Tsai CH. No association between TAP1 DpnII polymorphism and bronchopulmonary dysplasia. Acta Paediatr Taiwan. 2005; 46: 341-5.

16. Kim JH, Park BL, Pasaje CF, Bae JS, Park JS, Park SW, Uh ST, Kim MK, Choi IS, Cho SH, Choi BW, Park CS, Shin HD. Genetic association analysis of TAP1 and TAP2 polymorphisms with aspirin exacerbated respiratory disease and its FEV1 decline. J Hum Genet. 2011; 56:652-59.

17. Angkasekwinai P. Allergic inflammation and atopic disease: role of Th9 cells. Methods Mol Biol. 2017; 1585: 189-99.

18. Stemmler S, Hoffjan S. Trying to understand the genetics of atopic dermatitis. Mol Cell Probes. 2016; 30: 374-85.

19. Schmitz R, Atzpodien K, Schlaud M. Prevalence and risk factors of atopic diseases in German children and adolescents. Pediatr Allergy Immunol. 2012; 23: 716-23.

20. Dhingra N, Gulati N, Guttman-Yassky E. Mechanisms of contact sensitization offer insights into the role of barrier defects vs. intrinsic immune abnormalities as drivers of atopic dermatitis. J Invest Dermatol. 2013; 133: 2311-4.

21. Trowsdale J, Knight JC. Major histocompatibility complex genomics and human disease. Annu Rev Genomics Hum Genet. 2013; 14: 301-23.
22. Seyffer F, Tampé R. ABC transporters in adaptive immunity. Biochim Biophys Acta. 2015; 1850:449-60.

23. Panic N, Leoncini E, de Belvis G, Ricciardi W, Boccia S. Evaluation of the endorsement of the preferred reporting items for systematic reviews and meta-analysis (PRISMA) statement on the quality of published systematic review and meta-analyses. PLoS One. 2013; 8: e83138.

24. Xu YS, Jiang XJ, Chen JM. A single nucleotide polymorphism of AIRE gene located in the 21q22.3 increases the risk of rheumatoid arthritis. Oncotarget. 2017; 8:71556-62. https://doi.org/10.18632/oncotarget.17746.

25. Thakkinstian A, McEvoy M, Minelli C, Gibson P, Hancox B, Duffy D, Thompson J, Hall I, Kaufman J, Leung TF, Helms PJ, Hakonarson H, Halpi E, et al. Systematic review and meta-analysis of the association between \{beta\}2adrenoceptor polymorphisms and asthma: a HuGE review. Am J Epidemiol. 2005; 162: 201-11.

26. Cui L, Jia J, Ma CF, Li SY, Wang YP, Guo XM, Li Q, Yu HB, Liu WH, Gao LB. IL-13 polymorphisms contribute to the risk of asthma: a meta-analysis. Clin Biochem. 2012; 45: 285-8.

27. Yang G, Chen J, Xu F, Bao Z, Yao Y, Zhou J. Association between tumor necrosis factor-alpha rs1800629 polymorphism and risk of asthma: a meta-analysis. PLoS One. 2014; 9: e99962.

28. Lu Y, Liu W, Tan K, Peng J, Zhu Y, Wang X. Genetic association of RIT2 rs12456492 polymorphism and Parkinson's disease susceptibility in Asian populations: a meta-analysis. Sci Rep. 2015; 5: 13805.

29. Wang Y, Yang B, Ren X. Hsa-miR-499 polymorphism (rs3746444) and cancer risk: a meta-analysis of 17 casecontrol studies. Gene. 2012; 509: 267-72.

30. Duval S, Tweedie R. Trim and fill: A simple funnel-plotbased method of testing and adjusting for publication bias in meta-analysis. Biometrics. 2000; 56: 455-63. 